\title{
Erratum de : Interactions entre SAOS et chirurgie orthognathique
}

F. Barère ${ }^{1}$, M. Sapène ${ }^{2}$, Y. Mutel ${ }^{3}$, N. Raymond ${ }^{2}$, A. Andrieux ${ }^{4}$ et J. Forcioli ${ }^{5}$

1 Chirurgien maxillo-facial, Centre bordelais de chirurgie maxillo-faciale, Bordeaux, Pratique privée

2 Pneumologue, Bordeaux, Pratique privée

3 Spécialiste qualifié en ODF, Bordeaux, Pratique privée

4 Pneumo-pédiatre, Bordeaux, Pratique privée

5 ORL Bordeaux - Marseille, Pratique privée

Rev Orthop Dento Faciale, 50 (1) 41 - 58,

http://dx.doi.org/10.1051/odf/2015048

La reproduction de la figure 12c n'est pas correcte. L'éditeur s'excuse de cette erreur auprès des lecteurs et des auteurs.

La bonne version de la figure $12 c$ est indiquée ci-après.

Pour permettre de lire cette figure dans son contexte, voici la reproduction de la figure 12 en entier, avec sa légende.

Figure $12: a, b, c)$ Flèche violette = déplacement chirurgical, flèche rouge $=$ déplacement orthodontique, flèche incurvée = correction des versions, dent rouge $=$ dent extraite, point rouge $=$ extraction non systématique.

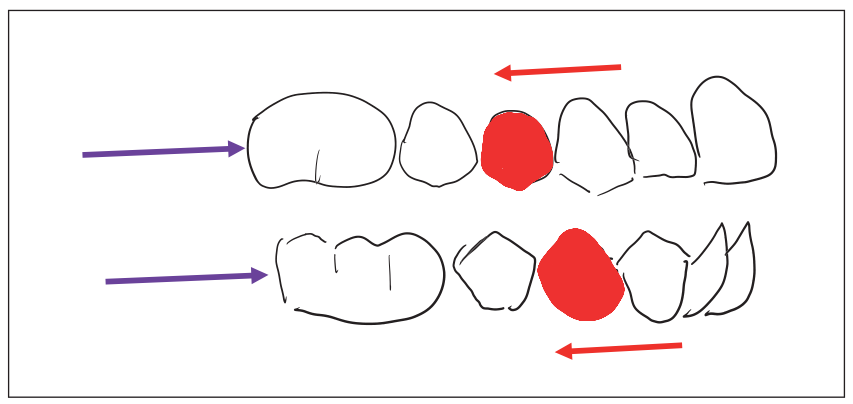

a

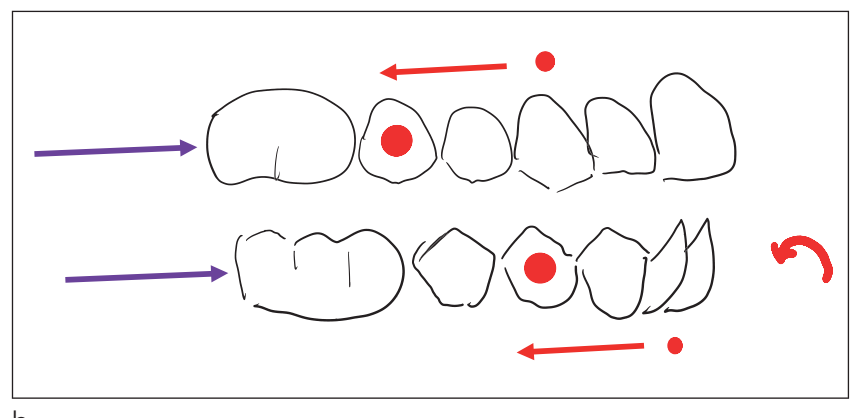

b

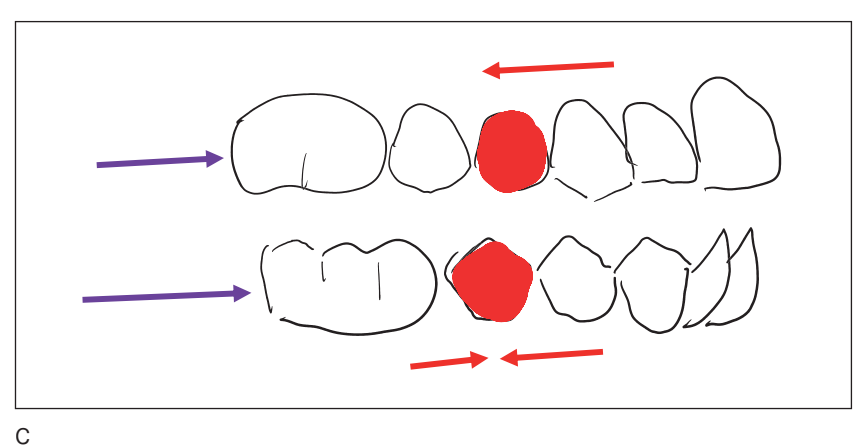

Adresse de correspondance : Frédéric Barère - Centre bordelais de chirurgie maxillo-faciale - 